\title{
Hepatitis $C$ and the sex trade
}

\author{
Stephen D Shafran MD FRCPC FACP
}

$\mathrm{I}^{\mathrm{t}}$ is well documented that female sex workers (FSWs) have high rates of substance abuse and sexually transmitted infections $(1,2)$. Hepatitis $\mathrm{C}$ virus (HCV) is a blood borne virus transmitted principally by parenteral exposures, most commonly from illicit injection drug use (IDU) in the 'developed' world and health care-related exposures due to inadequate infection prevention measures in the 'developing' world. Mother-to-child transmission occurs in approximately $5 \%$ of pregnancies among $\mathrm{HCV}$ viremic women (3).

Sexual transmission of HCV has been studied extensively, and heterosexual transmission is rare, estimated to be only one per 190,000 heterosexual contacts (4). In contrast, sexual transmission among HIV-infected men who have sex with men (MSM) is far more efficient and is an ongoing global challenge (5). Unprotected receptive anal intercourse and use of amphetamines are demonstrated risk factors for sexual transmission of HCV among HIV-infected MSM (5).

Multiple studies have examined the prevalence of HCV infection in FSWs (6-11). In some locations, FSWs have high rates of present or past IDU, placing them at high risk for HCV infection $(9,10)$. Studies that have controlled for IDU have not found higher rates of HCV infection among FSWs with no history of IDU (11).

The study by Socías et al (12) in the current issue of the Journal (pages 411-416), from An Evaluation of Sex Workers' Health Access (AESHA) cohort of FSW in Vancouver, British Columbia, purports to demonstrate gaps in the continuum of care for HCV among FSW. In fact, studies of the continuum of HCV care in the general population have shown very low rates of antiviral treatment. In Philadelphia (Pennsylvania, USA), it is estimated that only $15 \%$ of HCV-infected individuals receive antiviral therapy (13).

The study by Socías et al (12) is significantly limited by methodology. They relied entirely on patient self-reporting regarding HCV diagnosis, accessing HCV care, being offered anti-HCV therapy and receiving antiviral therapy. No effort was made to verify the data, even in a subset of patients.

The authors repeatedly suggest that the FSWs are at increased risk for HCV infection by the sexual route. To quote the authors "women sex workers in Vancouver had evidence of current/past HCV infection, likely due to the dual parenteral and sexual routes". This statement is patently false and detracts from the message that FSWs have high rates of $\mathrm{HCV}$ infection, because $51 \%$ of this cohort of women provided a history of IDU.

The authors also appear to misunderstand risk-based HCV testing. They defined it as "targeting individuals perceived to be at high risk for HCV infection, including people who use injection drugs, or with clinical or laboratory evidence of liver disease". These are not individuals 'perceived' to be at high risk for $\mathrm{HCV}$, they are proven to be at high risk for $\mathrm{HCV}$ infection. In fact, $>80 \%$ of Canadians with HCV infection have a history of IDU, and elevated serum alanine aminotransferase level is the most common reason physicians order HCV serology in patients of unknown HCV status.

The authors did not evaluate or discuss how to optimally engage FSWs in successful HCV care, which I define as achieving a sustained virological response (SVR) without re-infection. However, in another study of the AESHA cohort by several of the same authors, it was noted that $28 \%$ of HIV-infected FSWs had gaps in anti-HIV therapy of $>6$ months (14). Presumably, the proportion with gaps in anti-HIV therapy exceeding 12 weeks, the usual duration of interferon-free therapy for HCV, was higher still. Several of the authors have also reported that FSWs who continue to use illicit drugs have significantly lower rates of HIV suppression on antiretroviral therapy (15). Those who continue illicit drug use by injection face the additional risk of HCV re-infection, if they were to achieve SVR. To date, publicly funded drug plans in Canada restrict reimbursement to one course of therapy. Therefore, treating patients for HCV at high risk for re-infection, such as those still engaged in IDU, may not be the best strategy.

The solution to better health outcomes for FSWs is not simple, and some of the authors have made a meaningful contribution with a women-only sex work-specific drop-in centre in Vancouver (16); however, despite this novel clinic, they report suboptimal health outcomes. Other investigators have noted that drug-using sex workers frequently feel stigmatized when in conventional health care settings (17). Better health outcomes in FSWs for HCV and other health matters will require a multipronged approach, involving health care workers (including mental health workers), social scientists, educators, the criminal justice system and the community as a whole. Barriers financial and nonfinancial - to better health outcomes need to be removed. These efforts should result in making sex work less dangerous for those who continue in it, as well as identifying and facilitating transitions to viable vocational alternatives for those wishing to leave it. However, in the end, adult FSWs must want to have better health outcomes. Therefore, a large part of the solution is determining, through social science research, how to help FSWs come to the decision that they want to reduce harmful heath behaviours and pursue healthful ones, and then to apply implementation science so that they can maximally benefit from biomedical advances, such as interferonfree therapy, which can cure almost all patients of HCV infection. Interferon-free therapy for $\mathrm{HCV}$ is a tremendous advance, but it is only successful in those who complete it and then avoid behaviours that can result in re-infection.

\section{REFERENCES}

1. Morris MD, Lemus $\mathrm{H}$, Wagner KD, et al. Factors associated with pathways toward concurrent sex work and injection drug use among female sex workers who inject drugs in northern Mexico. Addiction 2013;108:161-70.

2. Verscheijden MM, Woestenberg PJ, Götz HM, et al. Sexually transmitted infections among female sex workers tested at STI clinics in the Netherlands, 2006-2013. Emerg Themes Epidemiol 2015;12:12.

3. Mast EE, Hwang LY, Seto DS, et al. Risk factors for perinatal transmission of hepatitis $\mathrm{C}$ virus (HCV) and the natural history of HCV infection acquired in infancy. J Infect Dis 2005;192:1880-9.

4. Terrault NA, Dodge JL, Murphy EL, et al. Sexual transmission of hepatitis $\mathrm{C}$ virus among monogamous heterosexual couples: The HCV partners study. Hepatology 2013;57:881-9.

5. Hagen H, Jordan AE, Neurer J, Cleland CM. Incidence of sexually transmitted hepatitis $\mathrm{C}$ virus infection in HIV-positive men who have sex with men. AIDS 2015;29:2335-45. 
6. Wang L, Tang W, Wang L, et al. The HIV, syphilis, and HCV epidemics among female sex workers in China: Results from a serial cross-sectional study between 2008 and 2012. Clin Infect Dis 2014;59:e1-9.

7. Laurent C, Henzel D, Mulanga-Kabeya C, et al.

Seroepidemiological survey of hepatitis $\mathrm{C}$ virus among commercial sex workers and pregnant women in Kinshasa, Democratic Republic of Congo. Int J Epidemiol 2001;30:872-7.

8. Todd CS, Nasir A, Stanekzai MR, et al. HIV, hepatitis B, and hepatitis $C$ prevalence and associated risk behaviors among female sex workers in three Afghan cities. AIDS 2010;24(Suppl 2):S69-75.

9. Johnston LG, Corseal S. Unexpectedly high injection drug use, HIV and hepatitis $C$ prevalence among female sex workers in the Republic of Mauritius. AIDS Behav 2013;17:574-84.

10. Taylor A, Hutchinson SJ, Gilchrist G, et al. Prevalence and determinants of hepatitis $\mathrm{C}$ virus infection among female drug injecting sex workers in Glasgow. Harm Reduct J 2008;5:11.

11. Kweon SS, Shin MH, Song HJ, Jeon DY, Choi JS. Seroprevalence and risk factors for hepatitis $\mathrm{C}$ virus infection among female commercial sex workers in South Korea who are not intravenous drug users. Am J Trop Med Hyg 2006;74:1117-21.
12. Socías ME, Shannon K, Montaner JS, et al. Gaps in the hepatitis C continuum of care among sex workers in Vancouver, British Columbia: implications for voluntary hepatitis $\mathrm{C}$ virus testing, treatment and care. Can J Gastroenterol Hepatol 2015;29:411-6.

13. Viner K, Kuncio D, Newbern EC, Johnson CC. The continuum of hepatitis C testing and care. Hepatology 2015;61:783-9.

14. Goldenberg SM, Montaner J, Duff P, etal. Structural barriers to antiretroviral therapy among sex workers living with HIV: Findings from a longitudinal study in Vancouver, Canada. AIDS Behav 2015; July 7 (Epub ahead of print).

15. Li T, Milloy MJ, Shannon K, et al. Suboptimal plasma HIV-1 RNA suppression and adherence among sex workers who use illicit drugs in a Canadian setting: An observational cohort study. Sex Transm Infect 2014;90:418-22.

16. Kim SR, Goldenberg SM, Duff P, et al. Uptake of a women-only, sex-work-specific drop-in center and links with sexual and reproductive health care for sex workers. Int J Gynaecol Obstet 2015; 128:201-5.

17. Whitaker T, Ryan P, Cox G. Stigmatization among drug-using sex workers accessing support services in Dublin. Qual Health Res 2011;21:1086-100. 


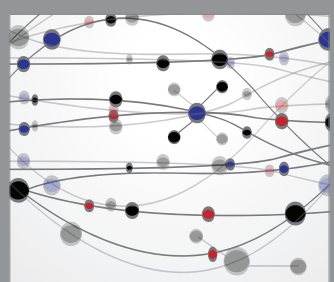

The Scientific World Journal
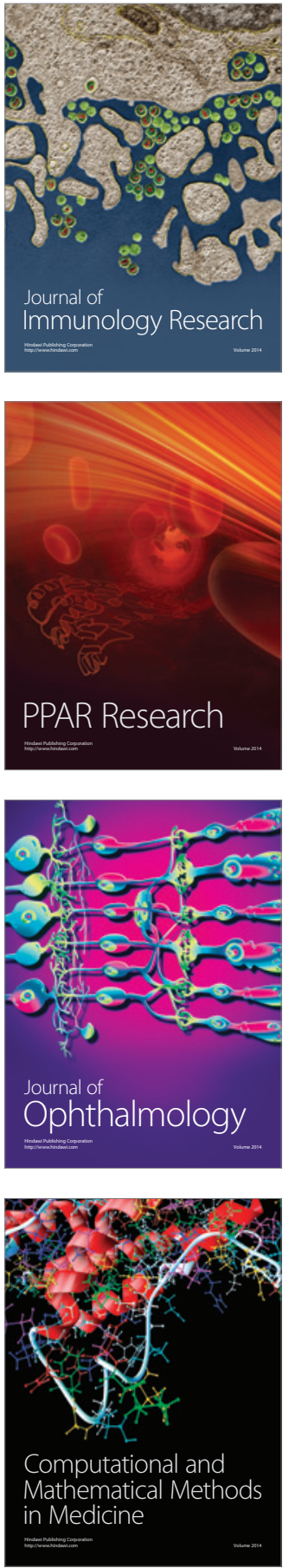

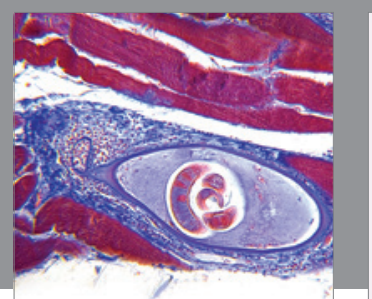

Gastroenterology Research and Practice

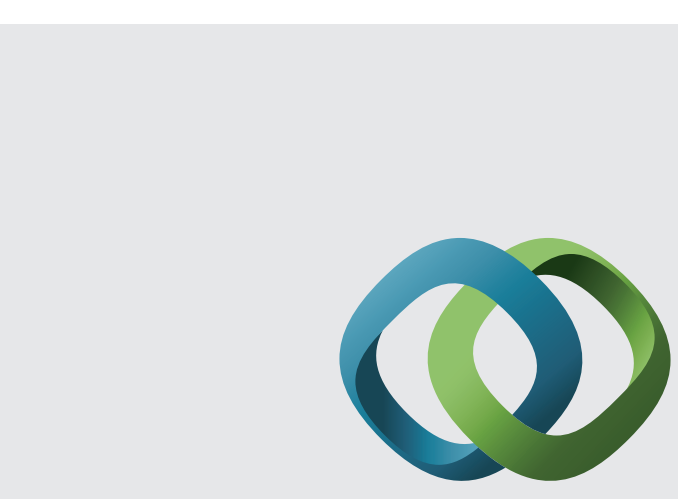

\section{Hindawi}

Submit your manuscripts at

http://www.hindawi.com
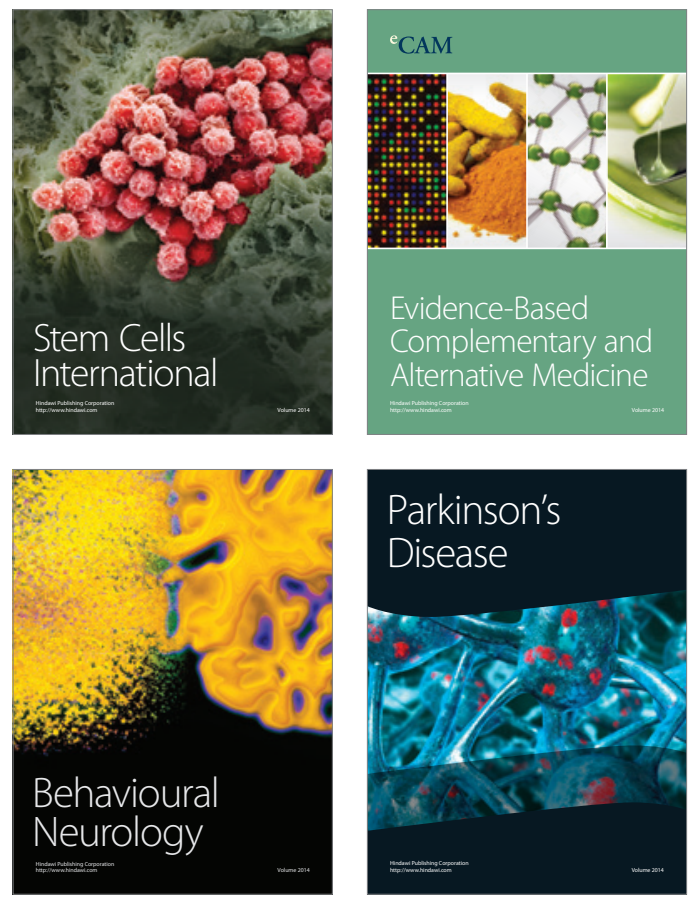
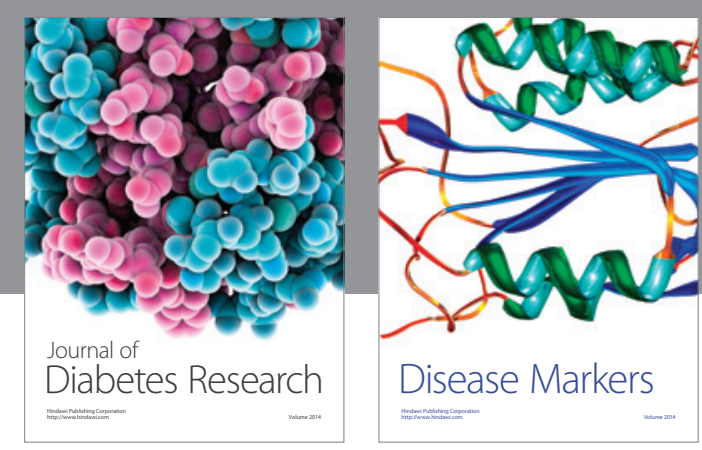

Disease Markers
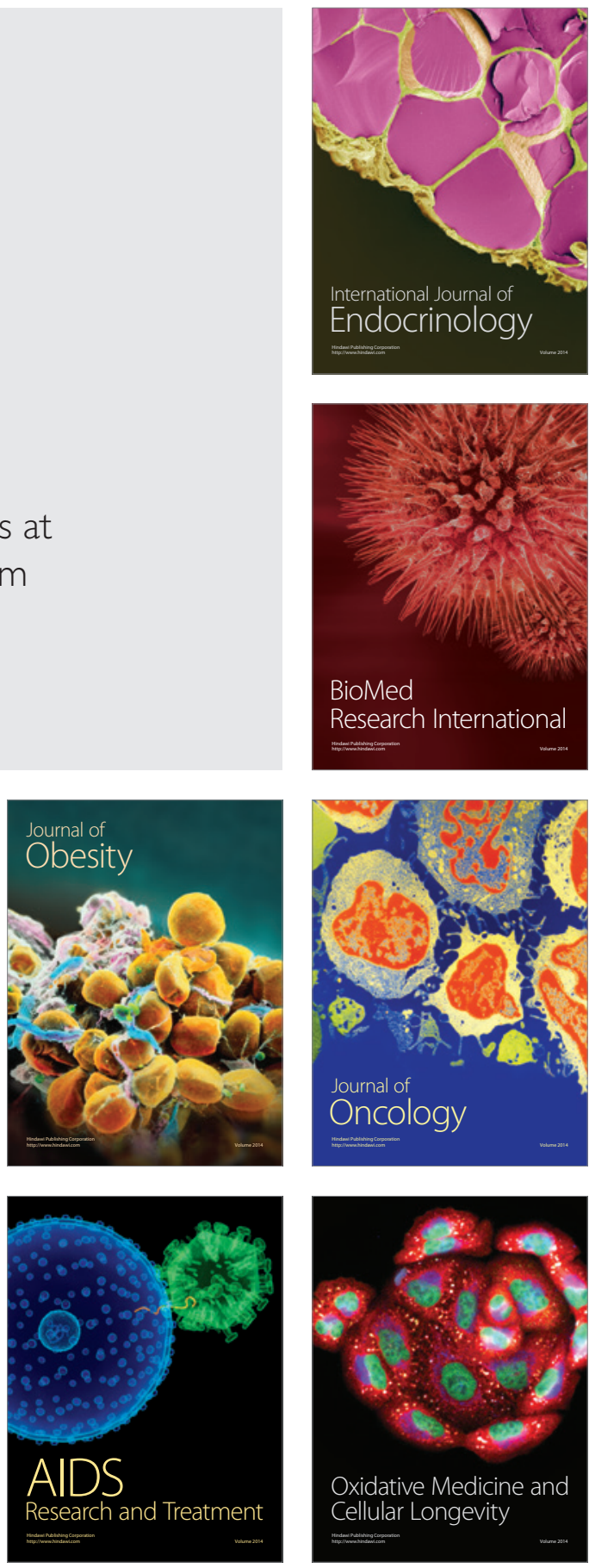